This item was submitted to Loughborough's Research Repository by the author.

Items in Figshare are protected by copyright, with all rights reserved, unless otherwise indicated.

\title{
Partnering to improve public transport in developing countries
}

PLEASE CITE THE PUBLISHED VERSION

PUBLISHER

(C) Thomas Telford Publishing

LICENCE

CC BY-NC-ND 4.0

\section{REPOSITORY RECORD}

Sohail, M., and D.A.C. Maunder. 2019. "Partnering to Improve Public Transport in Developing Countries". figshare. https://hdl.handle.net/2134/3883. 
This item was submitted to Loughborough's Institutional Repository (https://dspace.lboro.ac.uk/) by the author and is made available under the following Creative Commons Licence conditions.

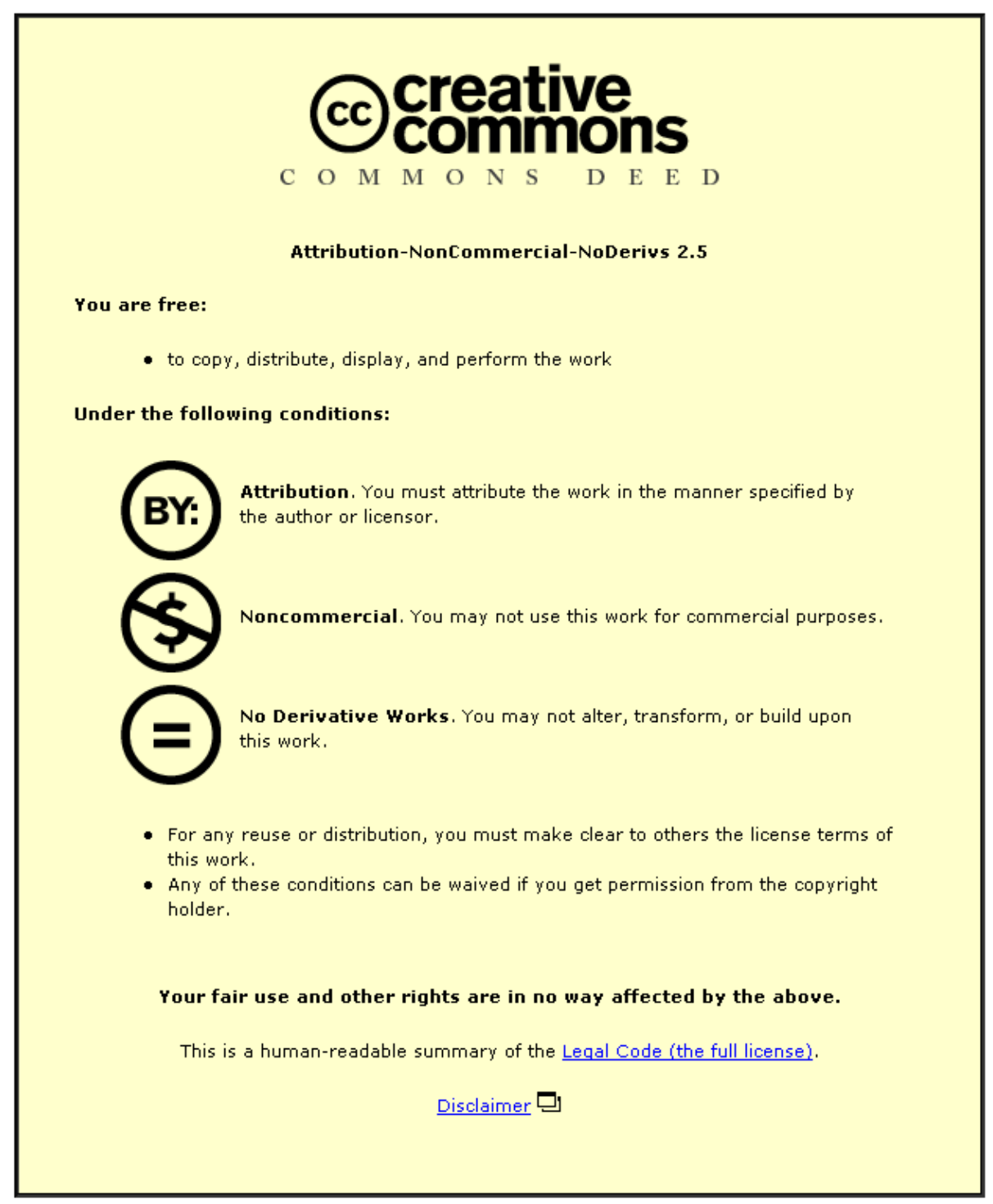

For the full text of this licence, please go to: http://creativecommons.org/licenses/by-nc-nd/2.5/ 


\section{Partnering to improve public transport in developing countries}

M. Sohail MSc, PhD, MASCE and D. A. C. Maunder BA, PhD, FCIT, MIHT

This paper demonstrates the importance of-and potential for-partnerships between the private and public sectors, and citizen groups, as a crucial means towards the improvement of public transport services in the developing world. It draws mainly upon the research findings of case studies in Karachi, Faisalabad, Dar es Salaam and Colombo between 1999 and 2003. The paper looks at some of the factors that need to be taken into consideration if a partnership is to be successful, before demonstrating the potential of existing links between users, operators and regulators. The potential for partnerships to improve upon the existing situation emerged on several occasions during the research, and these are summarised. Later sections look at the types of partnership that might be encouraged in the transport sector, as well as the importance of nurturing and supporting such partnerships. Finally, the paper highlights priorities for intervention-in the areas of infrastructure investment, land use and employment strategy, regulation and stakeholder collaboration-and the role partnerships could play in these interventions. The paper concludes with the importance of strengthening existing partnerships in public transport provision and creating and developing new ones. In this respect the authors consider it crucial that policymakers give due consideration to partnering approaches in the future.

\section{INTRODUCTION}

Transport is becoming the political paradigm not only in developed but also in developing economies. A substantial proportion of the population, if not a majority in many rapidly growing cities, live in low-income settlements. In the context of local politics, improvements in the quality of life of the urban poor in many cities of developing countries will be a key factor in attaining and sustaining political influence and power. Hence public transport is not just a technical issue but also has political or people dimensions. Urban public transport incorporates economic, human and social issues, and until the provision of public transport services becomes more people focused and environmentally friendly, equitable sustainable development will remain an unachievable dream. ${ }^{1}$

This paper reports on a significant part of the findings of a research project undertaken in Colombo (Sri Lanka), Faisalabad and Karachi (Pakistan) and Dar es Salaam (Tanzania) between 1999 and 2003. It is hoped that the findings will be useful for policymakers and urban public transport professionals so as to ensure that the poor will enjoy improved access to and quality of public transport services in the future, thereby widening economic opportunities and improving their lives in general. At present there is a lack of understanding about how services such as public transport are related to social and poverty issues. This paper contributes to the existing knowledge base by focusing on such issues, how they might be tackled via improved transport services, and, in particular, how such improvements might be achieved by encouraging partnerships in the transport sector.

Clearly, identifying key stakeholders, understanding roles and responsibilities and analysing the working linkages, relationships and mechanisms used to deliver public transport services are all fundamental to the improvement of services. In addition, this paper focuses on how existing partnerships can be strengthened and new ones fostered and developed to ensure that all stakeholders-including a wide range of users (young, aged, disabled etc.), regulators, administrators, planners and operatorsare included and all viewpoints considered. It also addresses the key issue of the contribution of partnerships (in public transport) in sustaining the livelihoods of the urban poor. ${ }^{2}$

Access to affordable transport is critical for the urban poor as it offers a way out of economic, social and physical isolation. The authors consider price, affordability, access and quality in relation to the provision of public transport services in three Asian cities (Karachi, Colombo and Faisalabad) and one African city (Dar es Salaam). For the purposes of the study public transport was defined as "the provision of transport that is consumed collectively (whether provided by the state or private sector) in which passengers pay a fare'. Primarily, modes of urban-based public transport include trains, light rail, buses and minibuses; however, taxis, trams and trolleys, metros and 'para-transit' modes such as rickshaws, bicycles and motorcycle taxis can also be included as public transport modes.

\section{WHY AND HOW THE RESEARCH WAS UNDERTAKEN}

The term partnership often means different things to different people. In this paper partnerships are defined as: 'non-adversarial relationships (both formal and informal) between stakeholders (people having a stake in the provision of public transport services)'. Such partnerships might involve public and private, 


\begin{tabular}{|lccc|}
\hline & $\begin{array}{c}\text { City } \\
\text { population } \\
\text { (est. 2000) }\end{array}$ & $\begin{array}{c}\text { Rate of } \\
\text { urban } \\
\text { growth: \% }\end{array}$ & $\begin{array}{c}\text { Rate of } \\
\text { urban growth } \\
\text { 1996-2000: \% }\end{array}$ \\
\hline Colombo & $690000^{*}$ & $2 \cdot 74$ & $2 \cdot 29$ \\
Dar es Salaam & 2347000 & 8.33 & $6 \cdot 31$ \\
Faisalabad & 2232000 & 4.14 & 4.31 \\
\hline
\end{tabular}

*Estimate for 1999

Source: United Nations. ${ }^{3}$

Table I. Statistics on city size and national rate of urban growth

public and public and/or private and private organisations/ partners. For the purposes of the study, 'public' is defined in relation to any government agency (for example a local authority, municipality or state) acting either directly (as a regulator) or indirectly (for example as principal where a commercial firm acts as the agent), and 'private' is said to relate to any other type of organisation involved in local government services (for example a private operator, a small-scale private provider or some type of community-based provision). The potential partners can be classified broadly as

(a) users

(b) operators

(c) regulators

(d) government policymakers

(e) support organisations, such as financial institutions.

Users can be individuals or a group. In all the case studies, the researchers noted that the mechanisms currently available for users to have a say in public transport services were very limited, particularly for the poor.

There are some glaringly obvious actions that should be taken to improve public transport services; it is not very clear what the factors are that inhibit undertaking those actions. For an example, see Appendix 1. The working hypothesis for the study was that the main inhibiting factor was a lack of partnering or collaborative working among all key stakeholders (operators, users and regulators). This study proposes that partnering can unlock the inaction. While relationships between agencies (and in some cases partnerships), both informal and formal, have responded in the past to provide the poor with access to public transport, there is a lack of understanding about how partnerships function to deliver public transport services as well as improve both the accessibility and quality of services.

The research problems below were explored in the case study cities of Karachi, Colombo, Dar es Salaam and Faisalabad. (See Table 1 for basic city data and for detailed cases studies please refer to references 4-7.)

(a) How can access to and quality of urban public transport services be improved?

(b) How can existing partnerships be strengthened and new ones fostered and nurtured in respect of public transport provision?

(c) How can the views of users, operators and regulators be integrated, and how should priorities be established at the operational and policy levels?

The predominantly 'how' nature of this research led to a case study approach. It was understood at the outset that case studies would not generate statistically representative generalisations, but would contribute to the logical explanation of events on the basis of both quantitative and qualitative data. (For a discussion of the merits of this approach see reference 8.)

The study locations of Faisalabad (Pakistan), Colombo (Sri Lanka) and Dar es Salaam (Tanzania) provided a variability of situation, which allows for a more rigorous approach to testing the viability or extension of findings. All the locations represent urban areas with significant numbers of poor people. However, different levels of private sector involvement in public transport provision, different levels of use of motorised transport and different cultural contexts enabled the authors to collect an extensive, rich database. The cities provided a useful sample of typical cities in South Asia and Eastern Africa. The local environment and the transport sector differ in each of the countries. The differences included the availability of modes of providing urban transport services and differences in the proportion of people who have access to public transport services. In Dar es Salaam, for instance, which really has only minibuses and conventional taxis, the poorest make use of minibuses; however, a high proportion of poor people are only able to afford to walk for most of their travel needs. The researchers thought it important to understand the reasons why this is so, how Dar es Salaam's poor can gain access to public transport services, and how the quality of those services can be improved through partnerships.

The research methodology included case studies using structured and semi-structured interviews, and a series of focus group discussions at residential settlements and at the city level, followed by an international workshop. Both quantitative and qualitative data were collected. Techniques included content analysis, literature reviews, historical analysis, case studies, a travel diary, focus group discussions, forums and workshops. Focus group and workshop attendees comprised users (including men, women, children, the elderly and disabled members of the community), operators and regulators.

Various issues were explored further in the study, such as pedestrian access to services, fares, reliability of services, how new routes/services are planned, and how local community views can be included in defining transport services. Some generic and thematic issues, which the researchers found to be important in the creation of a pro-poor public transport system, were also explored.

\section{I. Key perspectives}

Key perspectives were sought from:

(a) users, particularly low-income households

(b) providers and operators of the services, such as bus companies, drivers' associations, owners' associations

(c) regulatory agencies, primarily the transport ministry concerned and other government agencies, private bus companies, but also the municipal traffic departments and city traffic police who regulate the traffic and licensing authorities.

Approximately 300 interviews with key informants were conducted; 15 forums, three city-level workshops and one international workshop were held. In addition several sources of secondary data, including unpublished reports, were reviewed during the course of the case studies. 
The interview format for focus group meetings and interviews with key actors (users, operators and regulators) was a checklist developed from reviews, meetings and Phase 1 of the research. Necessary adjustments were made according to the specific requirements of the case study location; however, the general format of these interviews is given below.

(a) Users from selected settlements

(i) personal data

(ii) livelihood assets

(iii) travelling time

(iv) environment (waiting places, interior of vehicles)

(v) health and safety

(vi) modes and options

(vii) finances

(viii) corruption-related issues, which may be controlled by accountability and transparency

(ix) suggestions/ideas.

(b) Operators

(i) personal data

(ii) finances

(iii) major operational problems/issues

(iv) operation and maintenance

(v) corruption-related issues, which may be controlled by accountability and transparency

(vi) suggestions and ideas.

(c) Relationship between transport and livelihood patterns of the urban poor.

(d) Citizen initiatives to improve their access to transport.

\section{FINDINGS}

For case-specific research findings, please see the summary provided in Table 2. The following discussion is based on a cross-case analysis of findings.

\section{I. Key areas of contribution from partnerships}

For many years priority was given to publicly owned transport services, often at the cost of preventing private services from operating. ${ }^{9-14}$ However, as was shown by the experience in Dar es Salaam, where private bus operators were banned in 1975, such action does little to address transport needs. In this case private operators continued to provide services, albeit illegally, and in 1983 they were once more allowed to provide (limited) services. Colombo witnessed a similar situation between 1958 and 1979. At present both the private and public sectors provide transport services in all four cities, including Karachi. However, in all cases there is a complete lack of real collaboration or partnership between any of the different providers, or between a broad spectrum of other stakeholders and services providers.

Private sector involvement does not come free. On the one hand, the case studies show the benefits of involving the private sector (even informally) in the delivery of urban services such as public transport, where service provision was regarded previously as the domain of the public sector. On the other hand, there is evidence of the problems that can arise from a lack of regulation and regulatory capacity, poor service provision, and lack of affordability. There were some sort of inter-stakeholders, informally regulated mechanisms that were working, for example mafia control of timekeeping systems for the buses in Karachi, and some sort of regulatory mechanisms for vendors at bus stations in Dar es Salaam. Most of the outdated, non-consultative regulations existed only on paper.
Both access to and quality of public transport are still the key challenges. ${ }^{15,16}$ One possible strategy to prevent some of these problems from arising in the first place is through the use of a partnering approach or collaborative working between stakeholders to secure service improvements. Numerous opportunities for partnering are evident-in particular, within the private sector and between public agencies and private firms. One key stakeholder group that could become involved in such partnering arrangements is the users themselves, the regulatory agencies, and those responsible for government transport policy. Users in all the case cities do not have an effective organisational form to raise their voice. A weakness of one partner can be overcome through partnering, which then allows focus on the joint strength and the avoidance of an adversarial relationship.

\subsection{Examples of partnering in action}

It is important to recognise that generalised user groups may not be fully representative of all the interests of the poor. In Karachi, for example, the Karachi Public Transport Society addresses mainly the needs of higher-income groups. There is also a need to consider specific groups, such as those with disabilities who require access to safe public transport services to sustain their own medically constrained livelihoods. In some cases intermediaries have acted as representatives of such users in forums.

Operators are organised informally, for example in Colombo and Faisalabad, and in some cases formally, for example in Karachi, in the form of a bus owners' association. There is some evidence of inter-organisational collaboration or partnerships, but intra-organisational collaborative relationships were mostly absent. However, organisations are often effective only around short-term issues, such as promoting and implementing a fare increase.

Regulators are mostly organised formally, and in most cases such organisations are highly complex. They include various public sector organisations, including the police. For example, in Karachi it was estimated that there were around 60 organisations connected with the issue of public transport services, but even so there was no effective organisational hub for these groups. So even collaboration or partnerships among different elements of regulators were an issue. The scale of the potential problem of policy fragmentation was illustrated in the study of Dar es Salaam, in which four different ministries have an involvement in transport services: the Ministry of Communications and Transport; the Ministry of Finance (collecting taxes); the Ministry of Home Affairs (vehicle inspection); and the Ministry of Regional Administration and Local Government (with responsibilities including Dar es Salaam's transport licensing authority and route allocation).

Government policymakers and local government representatives are also important potential partners in their own right (as well as being the target of other partnerships) in terms of national and local transport initiatives. Again, there was hardly any mechanism to develop a policy in a collaborative manner. In most of the policy discourse there was hardly any representation from the users.

Support organisations may be both formal and informal. There are numerous support organisations, such as those providing 
Background Public transport availability has not grown at the same rate as the workforce.

Modes of

public

transport

Problems and illegalities in formal and informal transport sectors

Tongas (animal-drawn vehicle), conventional rickshaws, motorcycle

\section{Overcrowding} not enforced

Few proper bus stops

Poor condition of roads and rickshaws, buses, wagons and taxis. The market is dominated by Suzuki pick-ups.

Ban on smoking on public transport is pavements

Poor interior conditions of public transport

Bad behaviour of operators with passengers

Poor safety of children when travelling Loud music played by bus operators

Limited pedestrian crossings, signs for road safety.

City buses, wagons and pick-ups overcrowded inside and on the roof during peak hours

Manner in which passengers are picked up and dropped off

Corruption limited the provision and regulation of public transport
After two decades of nationalisation, in 1979 the government decided to permit private bus owners to operate regular services on all routes to complement/compete with public sector buses.

Pedal cycles, motor cars, motor cycles, Public transport is now provided by school vans and office staff transport, daladala buses, medium-sized Toyotathree-wheelers, private bus transport, rail transport, public buses.

Reckless drivers riding on pavements

Drivers not slowing down at pedestrian crossings

Unplanned stopping of buses

Bus shelters not maintained

Smoking prohibited but ban is not enforced

Bus drivers not stopping

Drunk driving

Drivers not having licence for/ experience of driving buses; lack of training/technical competence

Not following traffic regulations e.g. red lights

Conductors don't give the right change

Conductors harass girls and women

Informal businesses encroach on pavements

City is highly concentrated, with rapid population growth since the late 1940s. Historically, public transport was a government monopoly until 1983. DCM, Isuzu and Toyota Coaster buses, or buses that carry 20-22 people.

Pedestrian and cycle lanes are blocked by petty traders; parking places are also occupied by petty business. Bylaws not enforced by municipal councils and other stakeholders.

It is difficult to get compensation when a person has been involved in an accident, and comprehensive insurance is too costly: thus most owners opt for third party insurance.

Unnecessary seizures of vehicles by the traffic police, who solicit bribes for minor offences.

Drivers and conductors work as casual labourers and are not paid salaries.

Reckless driving and daladala buses cause traffic accidents and traffic jams. Vehicle operators do not follow traffic regulations or by-laws.

Lack of safety of pedestrians, cyclists and vendors

Overcrowding in peak hours/poor hygiene

Mistreatment of women and schoolchildren

Loud music, hooting, smoking on buses and pick-pockets

Public transport and the poor
There is a disparity of service between different parts of the city. Uneconomic for private operators to service routes on city outskirts off-peak.

Passengers' perspectives

Passengers complained that council has reduced spending on public transport.

Roads were not thought to be in good condition or wide enough.

$72 \%$ of respondents were unhappy with level of services they were offered through public transport. Complaints of dirty clothing after trips on buses or wagons.

$63 \%$ thought transport was dangerous. $90 \%$ thought overall standard was bad for passenger health.

The cost of transport is a high proportion of user incomes.
Public bus fares are affordable, because Current fare charges for buses are the fare is controlled by the Ministry of seen as too high, with many complaints Transport, but there are general complaints with pedestrian travel, frequency and time of operation of public transport, condition of transport modes, service crew and their performance.

Buses stops should be properly planned, and bus shelters with seating facilities should be constructed.

Minibuses and larger buses operate without timetables or bus stops, leading to traffic congestion and degradation of pavements.

Disputes frequently arise between minibus drivers and touts.

Lack of uniform makes it difficult to distinguish between unlicensed and licensed drivers.

Conductors were reported to use abusive language to women and girls who do not get off the bus quickly enough.

Buses were said to be unhygienic, particularly on hot days, leading to soiling and wrinkling of passengers' clothes. 
Vehicle owners' perspectives

Bus drivers' and conductors' perspectives

Regulation
$76 \%$ of employees were illiterate. Few crew members understood the mechanism of the vehicles they were driving/conducting.

Management controls were minimal. Drivers were trusted to return daily incomes to owners.

Little evidence exists that drivers or conductors are officially trained or had contracts for work.

Paid weekly or daily on the basis of targets. This meant drivers and conductors worked long days with short breaks.

$89 \%$ of drivers and conductors thought that traffic signals and signs were below standard.

Corruption exists in the police force: bribes were paid to avoid fines for offences such as driving without a licence, driving with full beam on at night, driving unfit vehicles, or overloading passengers.

The Regional Transport Authority has power to issue routes to all motorised vehicles, vehicle body manufacturing licences, check overloading, issue licences to goods forwarding agencies and impose penalties on violators.

The office of the Motor Vehicle Examiner issues and renews roadworthiness certificates for motorised public transport, and imposes penalties on violators.

The Traffic Police Department is responsible for issuing heavy/light transport vehicles licences, implementing traffic laws, controlling the flow of traffic, checking vehicle ownership, and watching for violators.

The Tax Branch are responsible for issuing licences/permits and enforcing by-laws for animal-drawn vehicles and imposing penalties on violators.
Government should coordinate private bus operations and ensure that private operators earn sufficient income.

Public-transport-related infrastructure should ensure that services can operate smoothly.

The route allocation system must prevent oversupply of buses.

Need for concessionary loan repayments/fuel subsidies.

Employment status of private bus conductors and drivers must be changed, with training, recognition and contracts.

Working conditions of crews must be changed.

Awareness raising of passengers of road safety.

A number of agencies do exist in Sri Lanka to guide and regulate public transport services. However, there is a lack of proper coordination at national as well as city level.

Regulatory agency personnel emphasise the need for all parties to cooperate in implementing traffic rules and regulations.

It has been observed that there are no significant partnership arrangements in operation in this sector.

Other transport modes, such as school vans, three-wheelers and office staff transport vans, are operated mostly on an individual basis, with no effective partnership arrangement between users, transport operators and regulators.

As well as roads, infrastructure such as pavements or cycle lanes is needed to make walking to work or school safe and accessible.

Traffic management measures such as one-way streets, removal of encroachments and better signalling would help.
Demands for tax relief on the running costs (spare parts and fuel) paid by owners of daladala.

Owners would like bus fares raised to cover operational costs.

Improvements to infrastructure of roads and terminals: shelters, benches, public toilets, drains, bus stops, parking bays.

Uniforms should be worn by drivers and conductors.

The Dar es Salaam Regional Transport Licensing Authority should be more transparent on the allocation of bus routes.

Vehicle owners suggested the need to establish a course on public transport issues.

Drivers and conductors have targets to meet. They work long days with little break.

Drivers' and conductors' lack of formal employment contracts with bus owners.

They stated a need for an association to safeguard employment and working hours.

They reported corruption in traffic police.

They requested more durable and comfortable uniforms.

Traffic department of the police force is responsible for designating and allocating routes to public bus operators. The Dar es Salaam Regional Transport Licensing Authority (DRTLA) is responsible for monitoring and enforcing route compliance among operators.

The police force is involved in inspecting vehicles for their roadworthiness and testing drivers for professional competency in driving.

There is no clearly defined urban public transport policy. 
Issues

Income inequality is high in Faisalabad, which causes problems for the pricing of public transport.

Inadequate infrastructure is a basic problem.

Many poor areas are not directly linked to main roads.

Traffic management measures such as one-way streets, removal of encroachments and better signalling are needed.

There is a need to development enforcement technology systems.
Consultation with the users and providers on public transport regulations should be institutionalised as part of policy formulation.

Partnerships should be promoted between different actors in public transport services.

Impacts of policies should be monitored through a participatory process.

Specific targets should be set, and time-bound actions are needed to achieve results.
Road transport network is poor, and does not encourage use of nonmotorised transport in parts of the city.

The fragmented provision of public transport makes it difficult to prepare focused plans or effective traffic management.

Public transport for schoolchildren needs special attention.

There is a need for alternative means of goods transport.

There is an urgent need to establish a forum for discussion whereby bus owners, operators and users would meet to discuss public transport. transport and maintenance services. There is a tendency for small-scale operators to seek assistance from informal support organisations, although these tend to be very costly to utilise, for example financing on very high rates. However, at the same time formal support organisations such as banks and other financial institutions have not even reached the stage of acknowledging the existence of informal potential partners.

For example, the lack of credit currently available to potential owners and operators is an illustration of how partnerships with financial institutions might offer benefits to the public if investment opportunities can increase, thereby increasing service provision. In a further example of the type of organisation that might be involved, in Faisalabad the Faisalabad Urban Transport Society (FUTS) is planning an arrangement with a minibus leasing company to increase the scale of services that it offers.

The current situation is illustrated by Figs 1 and 2, which show some links between potential partners. Existing links are mostly adversarial and uncoordinated. For example, the links in Karachi can be illustrated as shown in Fig. 2 .

The figures demonstrate how existing links can be converted into partnering links to improve the provision of public transport

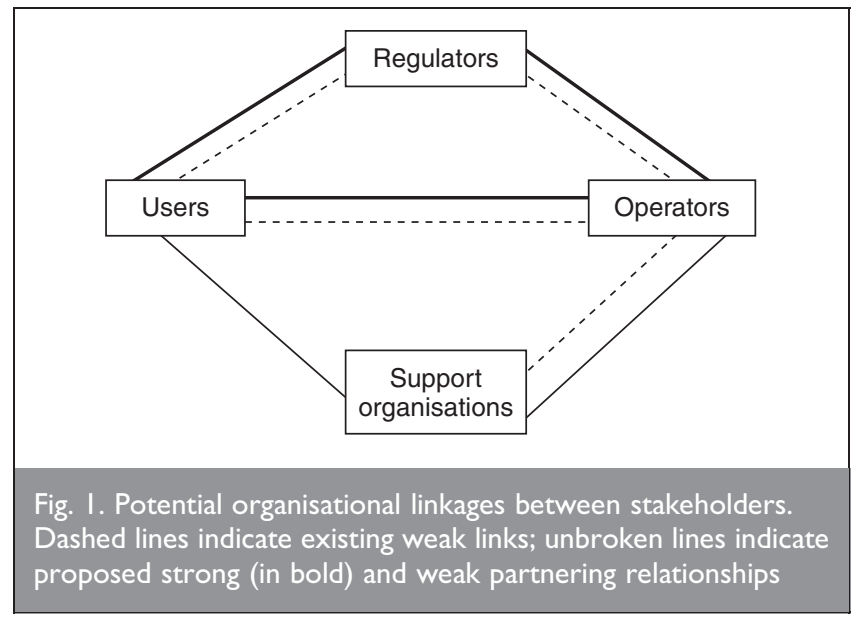

services. The potential for partnerships to improve the current situation emerged on several occasions within the case studies. For example, in Faisalabad the City Commissioner conceived and implemented FUTS, which is a voluntary organisation that provides a transport system and licenses over 1000 private vehicles to provide services. The objectives of the Society are to 'provide, maintain and supervise transport facilities for the commuters'. While the maximum number of vehicles on each route is not set, the operators themselves ensure that additional services are viable before allowing an additional bus. A single central terminal has assisted in the interchange of passengers between routes; nonetheless, congestion has resulted, and a second terminus is being developed.

A second and earlier example of a partnership in Faisalabad was that of the municipality's provision of eight stands for horse-drawn tongas (horse carts) in several places within the city. Such stands now provide the animals with some relief from the heat in the summer, and also offer animal drinking facilities. The choice of location of tonga station and how that service complements other modes was made in a collaborative manner.

In Karachi, both users and operators agree that speed humps (and other traffic-calming measures) would assist in enforcing speed restrictions. Clearly it is in everyone's collective interest

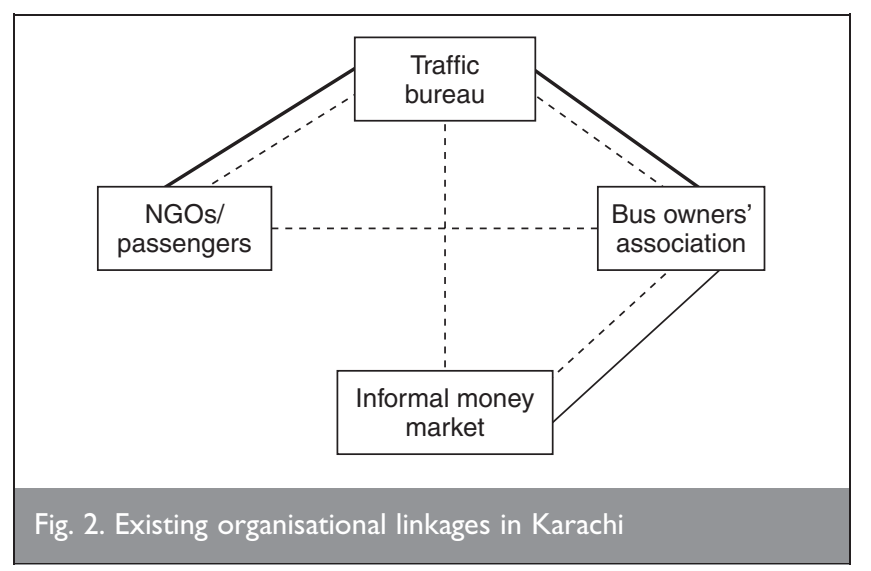


for vehicle speeds in dangerous places to be reduced. However, if such restrictions are not properly enforced for all operators, then each operator has an incentive to break restrictions to increase his potential number of passengers and consequently his earnings.

In Karachi there is a further example of the need for partnerships. The then government of Sindh (the province where Karachi is located) failed to include transport in the annual plan for 2000/ 2001, even though the ordinance establishing the Karachi Metropolitan Transport Authority had lapsed. Users, operators and regulators all have an interest in ensuring that transport remains on the policy agenda, otherwise funding will be difficult to earmark for transport improvements and maintenance of the city's existing network.

While partnerships may not address all the problems listed, they may offer a potential solution to some. Experience suggests that partnerships are likely to be most successful when 'win-win' solutions can be identified-that is, solutions that provide an incentive for both parties to be party to the agreement. Drawing on an example in the earlier study in Karachi, one citizens' group, SHEHRI, went to court to prevent the sale by the government of plots of land that had been intended for depots and workshops for city buses. In this case the alliance was between the users and the bus owners, both of whom wanted to retain the (potential) facility. Other opportunities for 'win-win' solutions emerged in the four case studies-for example, bus route improvements in Karachi, and improved visibility of daladala minibuses in Dar es Salaam.

A further example of a partnership within a specific sector of transport services was provided by the collaboration between bus operators in Karachi. Owing to the large number of buses being burnt in political unrest, and the non-availability of insurance cover, the operators themselves established their own insurance cover. Each member pays Rs.15 (£0.16) per day per bus, and the scheme then pays out whenever a bus is set on fire and damaged or destroyed. A final illustration of a partnership between different transport sectors also comes from Karachi. In 1997, a group of government officials and professionals from the private sector worked together with the Airport Security Force to improve traffic management at the airport. Two years later, activities were expanded to include a 14-kilometre road from the centre of town to the airport.

\subsection{Examples of intervention where partnering can} further work

In summary, transport services are essential for livelihoods, particularly in the peri-urban settlements of cities. ${ }^{17-22}$ However, transport costs may be unaffordable for the urban poor, even if the fares levied are considered fair in relation to the costs and risks incurred by the providers. Partnering arrangements can be devised to share the costs and risks. ${ }^{23-29}$ This is true of developed and developing countries: for example, in the UK local strategic partnerships (LSPs) in transport are a recent initiative intended to coordinate public services at a local level through community strategies and local neighbourhood renewal strategies. While travel conditions appear to be capable of considerable improvement if investment of various kinds is made available, public funds are usually already heavily committed, and low incomes are likely to limit the capacity of passengers to pay for such improvements. There may be merit in subsidies, which are widely used to ensure transport access at an affordable price for low-income groups and communities. However, the costs of subsidies are frequently high, and targeting may be weak.

There may well be a need for intervention, but this should be limited and assessed carefully in order to ensure that the effects are beneficial and make optimal use of scarce resources. Essentially, intervention may be targeted in four areas, all of which can benefit from partnering:

(a) infrastructure investment

(b) land use and employment strategy

(c) regulation of public transport services

(d) promotion of stakeholder collaboration.

\subsubsection{Infrastructure investment}

Inadequate infrastructure is a major hindrance to the operation of public transport services, and a cause of danger and discomfort to transport users. In this context, the main improvements that are required to improve transport services appear to be the following.

(a) Improving access to major roads from low-income residential areas to ensure that there are bus services at a reasonable distance to/from such areas. This might involve a partnership between government and the local community, for providing labour and skilled inputs. Alternatively, the public sector can encourage feeder services by para-transit modes from such localities to major road or bus routes (Fig. 3). Credit for those wishing to set up feeder services can be provided through partnerships with banks or informal lenders and the local community.

(b) Ensuring safe and secure bus stops for motorised transport with provision for shelter for passengers and designated areas for vendors. In particular, passengers are looking for somewhere to shelter, and somewhere where it is safe to wait. Local solutions need to be developed so that they are appropriate and low-cost. For example, experience in Faisalabad suggests that a public-private partnership involving private sponsorship may be a partial solution to the provision of bus stops, one that enables the public sector to focus its scarce resources within lower-income areas.

(c) Improving pedestrian routes that are also suitable for bicycles. This may be particularly important for some of the poorer households that cannot afford to pay for transport, and would reduce the difficulties they face in reaching major roads. Once more, appropriate local design is important. Attention should also be given to safety and the environment. For example, tree planting may be used to divide pedestrian routes from major roads.

\subsubsection{Land use and employment strategy}

A partial alternative to direct or indirect investment in public transport is for governments to improve the situation of the poor by applying a positive land use and employment strategy. Two measures could achieve this.

(a) identifying well-located land that is suitable for settlement by the urban poor, and which reduces the transport costs the resettled residents will face 


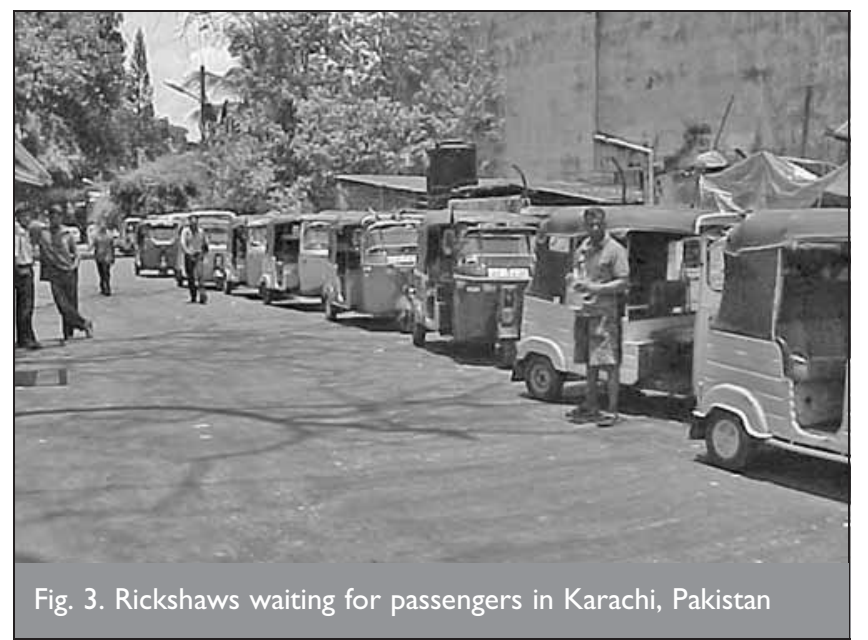

(b) encouraging employment opportunities within low-income settlements so as to minimise the distance that workers need to travel.

\subsubsection{Regulation}

Regulation of public transport services can be applied in three ways: over quality, quantity and price.

(a) Quality control in the stage bus industry concerns mainly the construction, maintenance and operation of vehicles, although it is also strongly affected by the behaviour of drivers and conductors and the quality of regular and preventive maintenance programmes. Such control is justified by the difficulty faced by consumers in assessing whether the vehicle they are boarding is safe, and the advantage in applying common minimum standards. In addition, from a quality and safety standpoint, it would be helpful if regulators made more effort to encourage owners to provide better conditions and security of employment for their drivers and conductors. As indicated in the study of Karachi, higher incomes are likely to result if higher-quality services are provided. Clearly some form of continuous dialogue and/or partnership arrangement between regulators and operators would ease the way as regards control over public transport quality.

(b) Quantity control, limiting the number of vehicles that may operate on a particular route, can bring about a more efficient and effective use of scarce resources, and minimise congestion (Fig. 4). However, control over the number of

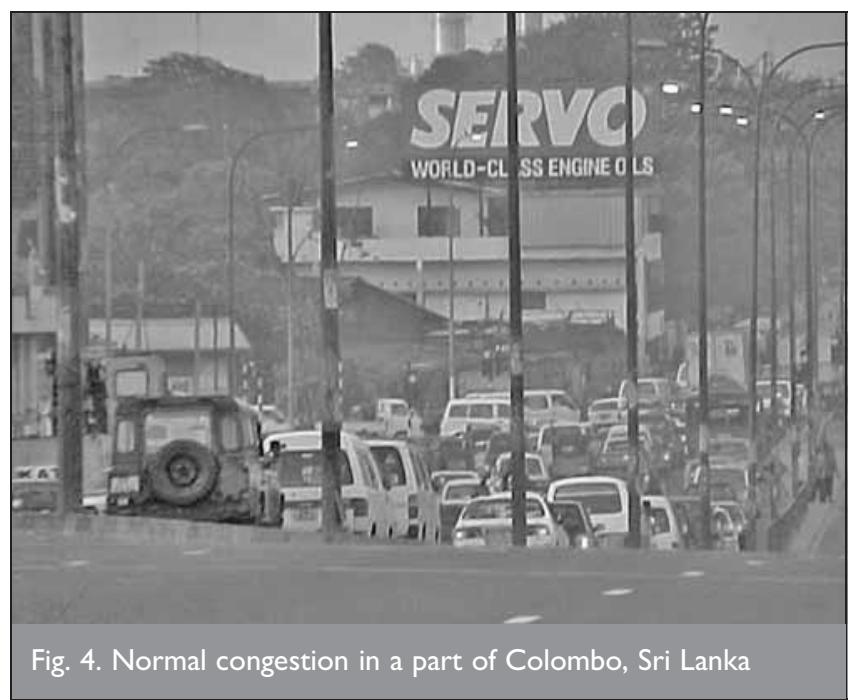

vehicles can also be anti-competitive and, by offering preference to a limited number of operators, such regulation can if misused offer potential advantages to those with undue or improper influence. Authorities may also be in danger of regulatory capture if they work too closely with the industry. However, the example of FUTS in Faisalabad suggests that it is possible to find a middle ground, restricting access to routes but being somewhat flexible. Clearly there is frequently excess supply on some routes, but such conditions are not in the interests of either users or the industry. Again, some form of dialogue/partnership between operators, regulators and potential operators is essential in this respect, and would be in the interests of all parties.

(c) Price control can be useful in avoiding excessive tariffs, particularly where quantity control limits competition. However, 'fair' tariffs are difficult to set, and there is again a danger of corruption if the regulator enjoys excessive powers. Moreover, transport providers are often able to avoid such controls. For example, they may refuse to transport low-paying passengers (such as students) and/or they might break their journey on a route arbitrarily to ensure a 'double' payment. Thus regulation, although necessary, should be light and unobtrusive, and should be applied only to meet well-considered and generally agreed objectives. Regular consultation with operators and users will also improve the chances of a consensus being reached on price/tariff controls.

Governments are also able to influence the structure of the industry more generally to seek improvements for users. For example, they may actively encourage the entry of private sector operators if they feel it is in the interest of the community as a whole to provide competition; alternatively, governments may seek a public monopoly for transport provision in some circumstances.

\subsubsection{Stakeholder collaboration}

Stakeholder collaboration can be promoted within various interest groups and also between groups in the form of partnerships.

(a) Owners' associations. With the fragmentation of ownership that characterises private transport services in all the study locations, there are likely to be benefits from encouraging operators to collaborate in order to raise standards and provide integrated services. There may also be benefits for regulators in being able to negotiate with a single group, although there is also a risk that an owners' association may form a cartel to exclude newcomers and protect the existing members' franchise.

(b) Users' associations. The priority that people give to transport was indicated by the significance of transport expenditures as a proportion of household income. There is a need for passengers' perspectives to be represented both to the industry and to government regulators. However, in none of the city locations were there any opportunities for transport users to enter into a dialogue with the providers or the transport authorities. User groups are likely to have an interest in working in partnership with many other groups within the sector, for example collaboration with the private sector to improve public provision for transport services.

(c) Stakeholder forums. Support could also be given to setting up a forum at which the various stakeholders in a city's transport 
sector can exchange views and experiences on a regular basis, either formally or informally.

There appear to be considerable opportunities to improve the existing provision of public transport services through partnerships among key stakeholders. Partnerships appear to be a significant missing link to improve access to and the quality of public transport services in a highly competitive market.

There are some general issues where the debate on partnering needs to move forward.

\subsubsection{Clarity in roles and responsibilities}

Partnerships may involve a coming-together of parties to address an issue of common interest. Such partnerships are characterised by the involvement of autonomous and independent organisations, each with something to contribute, and each party negotiating to establish the rules of collaboration.

Alternatively, a partnership may involve one party, usually the public sector, setting out a framework in which the role of the other party (or parties) is already defined. The need for clear and precise contracting arrangements in the provision of public transport cannot be overstressed. Contracts need to be tailored to suit local conditions, and it is here that significant differences are likely to be required between partnership contracts in 'northern' and 'southern' countries. The following generic options exist: service contracts; management contracts; leases and affermage contracts; franchise arrangements; and concessions. Please refer to Appendix 2 for a brief description of those categories of contract.

It is interesting to note that there is hardly a clear fit between the models of formal contract-based organisational linkages and what is happening in the case cities. The closest fit could be some sort of hybrid 'micro-concession' that is based on a particular route. There is scope for innovation in developing contracting arrangements to reflect the ongoing processes in the case cities.

\subsubsection{Nurturing partnerships}

Partnering is not discrete, but rather a continuous process. Of course, partners disagree, and complex arbitration systems may have to be established as a part of the partnership. However, experience suggests that such adversarial attitudes should be avoided if at all possible. To be successful, a partnership needs monitoring, maintenance and sustenance.

It should be emphasised that partnerships do not absolve the (public sector) regulators from their public responsibility, but merely shift the government's focus from managing the inputs of service provision to managing outcomes. There is a need for regulators to remain vigilant, carefully crafting principles and practices that create a supportive and credible environment, involving the right stakeholders in the right roles, and blending social and institutional dimensions of poverty reduction with the economic and financial gains of all partners.

Main constraints to partnering comprise

(a) lack of transparency and trust

(b) lack of professionalism

(c) lack of capacity.
There is a continuing need for processes to be open, fair and reasonable. Distrust is a function of perception and not necessarily of facts.

\subsubsection{Supporting partnerships}

What then are the lessons that have emerged from the case studies with respect to partnership support?

While the examples have illustrated that collaboration between the sectors is possible, partnership arrangements are clearly limited or completely lacking in the cities studied. For example, in Dar es Salaam: '... there is no dialogue between key actors, thus critical issues in the public transport service sector have not been resolved.' This quote emphasises that a first step to partnership is dialogue. A similar situation emerged from the study of Colombo. There are currently no partnership arrangements concerned with transport provision/infrastructure: hence little appears to be being undertaken to address transport needs. In Karachi and Faisalabad some experience of collaboration exists; however, there remains the need to strengthen and deepen existing initiatives and to create new ones.

As was argued in the Dar es Salaam report, it is the role of the state to "provide a platform for the various stakeholders in the sector (including operators and users) to meet and exchange views and derive opinions for addressing problems facing the sector'. A 'champion' is required to bring the parties together over an issue; only then can a sustainable partnership be realised, one that can address the issue/problem successfully. ${ }^{30}$ In the absence of another instigator, government should take the prime responsibility of bringing groups together; partnership arrangements may then occur between interested parties.

However, more than a simple bringing-together of different stakeholders is needed. In Faisalabad, for example, in a discussion with 16 drivers it emerged that only one had studied traffic rules and regulations. However, the majority of the group were dissatisfied with the implementation of traffic rules, and thought that there should be greater enforcement. Such contradictions need to be identified and suitable proposals put forward. Operators in this city recognised that service delivery would be improved through partnerships, especially those between three groups: public-private, private-private, and commercial banks-public/ private.

Partnerships are a means to an end rather than an end in themselves. Partnerships have to provide perceived benefits and incentives both for partners and for service users. Thus issues of equality and equity become relevant. Equality is an essential necessity to a partnership arrangement, so that everyone is treated on an equal basis and without feeling disempowered by the agreement. $^{31}$

\section{CONCLUSIONS}

If access to and quality of public transport in developing countries are improved, this could lead to a significant positive impact on the quality of life of the poor. However, neither the public nor the private sectors in these contexts are likely to be able to respond successfully if they act alone. At present there is a lack of understanding about how partnerships might improve access and quality of public transport in developing countries. 
This paper has demonstrated the importance of-and potential for-partnerships between the informal and formal private and public sectors, and citizen groups, as a crucial means towards the improvement of public transport services in the developing world.

Research findings of case studies in Karachi, Faisalabad, Dar es Salaam and Colombo between 1999 and 2003 were presented. The research was carried out in order to assess the current situation of public transport provision (by both state-run and privately operated services) in the four study locations, as well as to look at how access to and quality of public transport services might be improved.

While these cases provided few examples of good collaboration, they were instructive in highlighting how often opportunities for developing partnerships have been largely ignored by stakeholders. This paper also considered a number of factors that need to be taken into consideration if a partnership is to be successful, and examined the types of partnership that might be encouraged in the transport sector (see Appendix 2 for a description of contract categories). Priorities for intervention for the transport sector were described as infrastructure investment, land use and employment strategy, regulation and stakeholder collaboration-and the role that partnerships could play in these interventions was discussed. The key message of this paper is the importance of strengthening existing links between users, operators and regulators in public transport provision, and creating and developing new ones. The paper concludes with a discussion of what can be done to support and strengthen such relationships in order to improve accessibility and quality of public transport.

\section{ACKNOWLEDGEMENTS}

Support from the Department for International Development has enabled the authors to undertake this international research work. The views expressed here, however, are not necessarily those of DFID. The research was a collaborative effort between WEDC, Loughborough University, the International Institute for Environment and Development, and TRL Limited, with assistance provided by the University of Dar es Salaam, Sevanatha Urban Resource Centre Colombo, and Mr Attaullah Khan of Faisalabad, all of whose assistance is gratefully acknowledged. Special thanks go to Diana Mitlin (IIED), who was a social development expert in the project and provided valuable feedback to the authors on earlier drafts.

\section{APPENDIX I}

During an international workshop in Colombo in January 2003, where the findings from the research were presented, the participants were asked to list actions for improving access to and quality of public transport services for a given city. They came up with the following.

(a) Running buses on fixed timetables.

(b) Uniforms or an identity card being provided for drivers and conductors.

(c) The provision of continuous awareness programmes on passenger rights and responsibilities, as well as programmes for the operators (drivers/conductors).

(d) The introduction of by-laws for effective traffic management in the city. (e) The provision of regular training for operators and regulators.

$(f)$ The reintroduction of express and semi-express buses.

(g) The introduction of a metropolitan bus service in the city.

(h) The introduction of easy ticket-purchasing mechanisms, such as buying tickets from newspaper stands.

(i) The provision of terminal facilities to be used by a number of different vehicle modes.

(j) Proper maintenance being carried out on bus shelters.

(k) The provision of adequate pavements in the city.

(l) Regulation of para-transport (i.e. informal modes such as three-wheelers, auto rickshaws).

(m) An increase in government-operated school bus services.

(n) The promotion of bicycle use.

Interestingly, cost did not feature, but many of the improvements mentioned appear to be relatively straightforward. However, in all the case studies such actions were generally missing; the authors wonder why.

\section{APPENDIX 2. A SET OF CONTRACT CATEGORIES}

The most common approach is the service contract, which is characterised by the client (usually the public sector, a local government or municipality, for example) contracting out services to a private firm for an agreed level of provision within defined specifications and for a fixed period of time.

Management contracts are somewhat more complex than basic service contracts. Again the client retains ownership of the assets and is responsible for capital expenditure, working capital and the commercial risk of the collection of service fees. The contract is normally output based. The private party manages the provision of the service without committing significant investment capital, and without accepting much risk.

Leases and affermage contracts provide for the client to lease infrastructure and facilities to a private firm, which will then have exclusive rights to operate and maintain the system for a fixed period of time. The main feature distinguishing these contracts from a management contract is that the private operator bears the commercial risk of non-payment of fees and charges. There is no transfer of ownership, and the client remains responsible for capital investment required to upgrade or extend the system.

Franchise arrangements are based upon granting exclusive rights to a private firm to provide a type of service within a specific geographical area. Such arrangements are often for waste collection and treatment services. Instead of leasing facilities and infrastructure, the operator is given the right to deliver a service in return for a payment, and will in turn levy charges for the delivery of the service and/or for generating income from the service through other means, such as selling by-products.

Concessions entail the client (usually a municipality) transferring full responsibility for service delivery in a specified area to a concessionaire (a private contractor). The private firm's responsibilities usually include all construction, maintenance, collection and management activities. The concessionaire is also responsible for all capital investment to build, upgrade or extend the system. The client will generally retain responsibility for establishing and monitoring performance standards, and for the regulation of price and service volumes. 
This regulatory authority is crucial in public goods that have monopoly characteristics. The main feature distinguishing a concession from a lease is the additional responsibility that the private sector has for financing capital investment. Although the fixed assets are entrusted to the concessionaire for the agreed period (usually 25 years), they still remain the property of the client.

\section{REFERENCES}

1. SoHAIL M. Potential role of urban transport in assets and employment creation for the poor. Proceedings of Work 2001: First International Conference on Employment Creation in Development, University of Witwatersrand Johannesburg, South Africa, 2001, pp. 169-178.

2. Sohail M., Mitlin D. and Maunder D. A. C. Guidelines: Partnerships to Improve Access and Quality of Public Transport. WEDC, Loughborough University, 2003.

3. United NATIONs. World Urbanization Prospects: The 1999 Revision. United Nations (Population Division), New York, 2001.

4. SoHAIL M. (ed.) Urban Public Transport and Sustainable Livelihoods for the Poor. A case study: Karachi, Pakistan. WEDC, Loughborough University, 2000.

5. Sevanatha Urban Resources Centre. A Case Report: Colombo, Sri Lanka. WEDC, Loughborough University, 2003.

6. Kombe W., Kyessi A., Lupala J. and Mgonja E. A Case Report: Dar-es Salaam, Tanzania. WEDC, Loughborough University, 2003.

7. Khan A. U. A Case Report: Faisalabad, Pakistan. WEDC, Loughborough University, 2003.

8. YIN R. Case Study Research: Design and Methods. Sage, London, 1994.

9. White P. Public Transport: Its Planning, Management and Operation, 4th edn. ECtFN Spon, London, 2002.

10. Estache A. Privatization and Regulation of Transport Infrastructure in the 1990s: Successes and Bugs to Fix for the Next Millennium. World Bank, Washington, DC, 1999, Policy Research Working Paper 2248.

11. Brake J., Nelson J. D. and Wright S. Demand responsive transport: towards the emergence of a new market segment. Journal of Transport Geography, 2004, 12, No. 4, 323-337.

12. ORN H. Urban Traffic and Transport. Housing Development and Management, Lund University, Sweden, 2002, part of the Building Issues series, vol. 12, No. 2.

13. Armstrong-Wright A. and Thiriez S. Bus Services: Reducing Costs, Raising Standards. World Bank, Washington, DC, 1987, World Bank Technical Paper Number 68, Urban Transport Series.

14. GANnon C. and Liu Z. Transport: Infrastructure and Services. Poverty Reduction Strategy Paper (PRSP) Sourcebook. World Bank, Washington, DC, 2000.

15. World BANK. Urban Transport: A World Bank Policy Study. World Bank, Washington, DC, 1986.
16. VAsconcellos E. A. Urban Transport, Environment and Equity: The Case for Developing Countries. Earthscan, London, 2001.

17. Ashley C. and CARNEY D. Sustainable Livelihoods: Lessons from Early Experience. Department for International Development, London, 1999.

18. Bryceson D. F., Maunder D. A. C., Mbara T. C., Kibombo R. and Howe J. D. G. F. Sustainable Livelihoods: Mobility and Access Needs. Transport Research Laboratory, Crowthorne, 2003, TRL Report 544.

19. Department For International DeVelopment. Livelihoods of Poor People: What Contributions Can Transport Make? Workshop Report. Department for International Development, London, 1999.

20. Fouracre P. R. and Maunder D. A. C. Travel Demand Characteristics in Three Medium-Sized Indian Cities. Transport Research Laboratory, Crowthorne, 1987, TRL Research Report RR 121.

21. Palmer C., Astrop A. and Maunder D. A. C. Constraints, Attitudes and Travel Behaviour of Low-Income Households in Two Developing Countries. Transport Research Laboratory, Crowthorne, 1997, TRL Research Report 263.

22. BARTER P. A. Transport and urban poverty in Asia: a brief introduction to the key issues. Regional Development Dialogue, 1999, 20, No.1, 143-163.

23. Estache A. and DE RUS G. Privatization and Regulation of Transport Infrastructure: Guidelines for Policymakers and Regulators. World Bank, Washington, DC, 2000.

24. Pedersen P. O. The Changing Structure of Transport Under Trade Liberalization and Globalization and Its Impact on African Development. Centre for Development Research, Copenhagen, 2000, CDR working papers; 00.1. Working paper sub-series on globalisation and economic restructuring in Africa No. vii.

25. Cervero R. Informal Transport in the Developing World. United Nations Centre for Human Settlements (Habitat), Nairobi, 2000.

26. URBAN RESOURCE CENTRE. Urban poverty and transport: a case study from Karachi. Environment and Urbanization, 2001, 13, No. 1, 223-233.

27. Howe J. and BRYCESON D. Poverty and Urban Transport in East Africa: Review of Research and Dutch Donor Experience. IHE, The Hague, 2000.

28. Jamieson Mackay Ct Partners. The Minibuses and Public Transport systems of Kuala Lumpur. Transport Research Laboratory, Crowthorne, 1981, TRL Report SR 678.

29. Maunder D. A. C. and Mbara T. C. The Effect of Ownership on the Performance of Stage Bus Services in Harare, Zimbabwe. Transport Research Laboratory, Crowthorne, 1993, TRL 123.

30. GAKENHEIMER R. Urban mobility in the developing world. Transport Research A, 1999, 33, No. 7, 671-689.

31. Vasconcellos E. A. Urban Transport, Environment and Equity: The Case for Developing Countries. Earthscan, London, 2001.

\section{What do you think?}

To comment on this paper, please email up to 500 words to the editor at journals@ice.org.uk

Proceedings journals rely entirely on contributions sent in by civil engineers and related professionals, academics and students. Papers should be 2000-5000 words long, with adequate illustrations and references. Please visit www.thomastelford.com/journals for author guidelines and further details. 